\title{
Selective Regulation of N-Type Ca Channels by Different Combinations of G-Protein $\beta / \gamma$ Subunits and RGS Proteins
}

\author{
Janice Y. Zhou, ${ }^{1}$ David P. Siderovski, ${ }^{2}$ and Richard J. Miller ${ }^{1}$ \\ ${ }^{1}$ Department of Neurobiology, Pharmacology, and Physiology, University of Chicago, Chicago, Illinois 60637, and \\ 2Department of Pharmacology, University of North Carolina, Chapel Hill, North Carolina 27599
}

\begin{abstract}
We examined the effects of G-protein $\beta$ and $\gamma$ subunit heterodimers on human $\alpha_{1 \mathrm{~B}}$ (N-type) $\mathrm{Ca}$ channels expressed in HEK293 cells. All of the known $\beta$ subunits $(\beta 1-\beta 5)$ produced voltage-dependent inhibition of $\alpha_{1 \mathrm{~B}}$ Ca channels, depending on the $\gamma$ subunit found in the heterodimer. $\beta 1-\beta 4$ subunits inhibited Ca channels when paired with $\gamma 1-\gamma 3$. However, $\beta 5$ subunits only produced inhibition when paired with $\gamma 2$. In contrast, heterodimers between $\beta 5$ subunits and RGS (regulators of G-protein signaling) proteins containing GGL domains did not produce inhibition of Ca channels. However, GGL domain-containing RGS
\end{abstract}

proteins (e.g., RGS6 and RGS11) did block the ability of $G \beta 5 / \gamma 2$ heterodimers to inhibit $\mathrm{Ca}$ channels. Because all of the G-protein $\beta$ subunits are found in the nervous system, we conclude that they may all potentially participate in Ca channel inhibition. The interaction of GGL-containing RGS proteins with $\mathrm{G} \beta 5 \gamma 2$ suggests a novel way in which $\mathrm{Ca}$ channels can be regulated.

Key words: heterotrimeric G-proteins; calcium channel; ionchannel modulation; RGS proteins; presynaptic inhibition; synaptic transmission
Activation of G-protein-coupled receptors (GPCRs) by neurotransmitters has been shown to induce the inhibition of several types of voltage-sensitive $\mathrm{Ca}$ channels, including $\alpha_{1 \mathrm{~B}}$ (N-type), $\alpha_{1 \mathrm{~A}}$ (P/Q-type), and $\alpha_{1 \mathrm{E}}$ (R-type) (Miller, 1998; Simen and Miller, 1998, 2000). The resulting reduction in $\mathrm{Ca}$ influx may be important for GPCR-mediated inhibition of neurotransmitter release (Miller, 1998). Investigations of the mechanisms underlying GPCR-mediated Ca channel inhibition have shown that different processes can occur. The best studied of these is rapid and is characterized by its voltage dependence (Hille, 1994; Miller, 1998). The view is widely held that $\mathrm{Ca}$ channel inhibition of this type is mediated by the direct binding of G-protein $\beta / \gamma$ subunits to one or more sites on the Ca channel $\alpha 1$ subunit (Herlitze et al., 1996; Ikeda, 1996; J. F. Zhang et al., 1996; Qin et al., 1997; Simen and Miller, 1998, 2000; Canti et al., 1999). According to this model, activation of any GPCR should produce inhibition of Ca channels, because $\beta / \gamma$ subunits are always released. However, this is clearly not the case, and there are many examples of GPCR activation that does not produce voltage-dependent inhibition of $\mathrm{Ca}$ channels (Bernheim et al., 1991; Taussig et al., 1992; Shapiro and Hille, 1993; Hille, 1994; Shapiro et al., 1994; Liu et al., 1995; Margeta-Mitrovic et al., 1997). In many cases these GPCRs are linked to G-proteins of the $\alpha \mathrm{q} / \alpha 11$ family. However, the reasons for this selectivity are not clear. One possibility is that not all combinations of $\beta / \gamma$ subunits are equally effective in inhibiting $\mathrm{Ca}$ channels. There are at least 5 types of $\beta$ subunits, all of which are found in the nervous system (Betty et al., 1998), and at least 11 types of $\gamma$ subunits; therefore, many $\beta / \gamma$ combinations are potentially possible (Morris and Malbon, 1999). Garcia et al. (1998) examined this question by analyzing the effects of expressing different $\beta$ subunits in cultured rat superior cervical ganglion (SCG) neurons. They observed that only $\beta 1$ and $\beta 2$ produced strong voltage-dependent $\mathrm{Ca}$ channel inhibition, whereas $\beta 5$ and, particularly, $\beta 3$ and $\beta 4$ were weak in

\footnotetext{
Received June 1, 2000; revised July 10, 2000; accepted July 12, 2000.

This study was supported by US Public Health Service Grants DA-02121, DA13141, DA-44840, MH-40165, NS-33826, and NS-21442. We thank Dr. C. Lee for helpful suggestions and comments throughout the project and D. Ren for excellent technical assistance. We are grateful to Drs. A. Gilman and A. Krumins for kindly providing cDNA for RGS proteins, to Dr. Katz for $\mathrm{G} \gamma$ subunit cDNA, and to SIBIA Neuroscience for cell lines expressing $\alpha 1 \mathrm{~B}$ Ca channels.

Correspondence should be addressed to Dr. Richard J. Miller, Department of Neurobiology, Pharmacology, and Physiology, University of Chicago, 947 East 58th Street (MC 0926), Chicago, IL 60637. E-mail: rjmx@midway.uchicago.edu. Copyright (C) 2000 Society for Neuroscience $0270-6474 / 00 / 207143-06 \$ 15.00 / 0$
}

this regard. Because $\mathrm{G} \alpha_{\mathrm{q}}$ is often thought to associate with $\beta 5$ (Fletcher et al., 1998), it could be argued that lack of effect of $\beta 5$ was responsible for the modest $\mathrm{Ca}$ channel inhibition observed with GPCRs of this type. Recently, however, Ruiz-Velasco and Ikeda (2000) reexamined this question and observed that all $\beta$ subunits could produce inhibition of $\mathrm{Ca}$ channels in rat sympathetic neurons under the appropriate conditions.

In the present series of experiments we examined this question further using cloned human $\alpha_{1 \mathrm{~B}}$ (N-type) Ca channels and different combinations of $\beta / \gamma$ subunits. Our data indicates that all of the $\beta$ subunits can inhibit $\mathrm{Ca}$ channels, but that this is dependent on the nature of the $\gamma$ subunit present in the $\beta / \gamma$ heterodimer. Moreover, the effects of some $\beta / \gamma$ combinations are influenced by RGS (regulators of G-protein signaling) proteins, suggesting a novel mechanism through which these proteins may regulate neuronal Ca channels.

\section{MATERIALS AND METHODS}

Expression constructs. Mouse G $\beta 4$ (GenBank accession number M87286) was prepared from adult male CD 4 mouse brain mRNA. Human G $\beta 1$ (X04526), G $\beta 2$ (NM 005273), G $\beta 3$ (NM 002075), and G 35 (AF017656) were obtained from human embryonic kidney (HEK) cell line mRNA (Quick Prep Micro mRNA purification kit; Amersham Pharmacia Biotech, Piscataway, NJ). $\beta$ subunit cDNAs were amplified from the isolated mRNA by reverse transcription-PCR (thermal cycling: $98^{\circ} \mathrm{C}, 20 \mathrm{~min} ; 56^{\circ} \mathrm{C}$, $1 \mathrm{~min} ; 72^{\circ} \mathrm{C}, 1.5 \mathrm{~min} ; 35$ cycles, preceded by a $3 \mathrm{~min} 98^{\circ} \mathrm{C}$ denaturing) with SuperScript II reverse transcriptase (Life Technologies, Rockville, MD) and oligo-dT oligonucleotides and then with specific primers and TakaRa LA Taq DNA polymerase (PanVera, Madison, WI). Subunit specific primers used here were as follows: $\beta 1$ forward $(\beta 1 \mathrm{~F})$, GCCGCCACCATGAGTGAGCTTGACCAGTTACGGCAGGAG; $\beta 1$ reverse $(\beta 1 \mathrm{R})$, CTTAGTTCCAGATCTTGAGGAAGCTATCCCA; $\beta 2 F$, GCCGCCACCATGAGTGAGCTGGAGCAACTGAG; $\beta 2 \mathrm{R}$, CCATTAGTTCCAGATCTTGAGGAAGG; $\beta 3 \mathrm{~F}$, GCCACCATGGAGCAACTGCGTCAGGAAGC; $\beta 3 R$, CCACTTCCCTTTCTCCAGCCTCC; $\beta 4 F$, GCCACCATGAGCGAGCTGGAGCAGCTGA; $\beta 4 R$, CTCCATGTATCATTGGAGAACAG; $\beta 5 \mathrm{~F}$, GCCGCCACCATGGCAACCGAGGGGCTGC; and $\beta 5 \mathrm{R}$, GATGATTAGGCCCAGACTCTGAG.

All constructs contained an expression-optimized Kozak sequence (GCCACC) before the $5^{\prime}$-ATG start codon. The resulting amplification products were first cloned into pCRII/TOPO vector (Invitrogen, San Diego, $\mathrm{CA}$ ) for verification. Verified constructs were directionally cloned into a mammalian expression vector driven by the cytomegalovirus (CMV) promoter ( $\mathrm{G} \beta 1$ was cloned in pCMV6C; $\mathrm{G} \beta 2, \mathrm{G} \beta 3$, and $\mathrm{G} \beta 5$ were cloned in pcDNA3.1; and $\mathrm{G} \beta 4$ was cloned in pCR3.1). The resulting clones were verified by restriction enzyme digestion and automated DNA sequencing (ABI 377 sequencer; Perkin-Elmer, Oak Brook, IL). G $\gamma 1$ was subcloned in pCDNA1, G $\gamma 2$ in pCDM8.1, and $\mathrm{G} \gamma 3$ in pCDNA1 (gifts from Dr. Katz, 
Caltech). Green fluorescent protein (GFP) vector is commercially available from Life Technologies.

The RGS11n construct encoding the N-terminal half of the RGS11 protein contains DEP and GGL domains, and the RGS11c construct encoding the C-terminal half of the RGS11 protein contains an RGS domain. They were generated by PCR (T7 primer with R11R, CTTCGTGGGGGCAGCCTCGAGGGGGGCATTCATGAC; and pcDNA3.1R primer with R11F, GTGGTGGAATTCGACCATGCCGCATCTGAGGAAGATGGAGCGGGTGGTCGTGAGCATGCAGG

ACGTCATGAATGCCCCCACGGTGGCT) using pfu DNA polymerase (Stratagene, La Jolla, CA) and were subcloned into a pcDNA3.1 vector. The two constructs were designed to have the same sequence around the start codon as in full-length RGS11 to achieve similar expression levels Full-length RGS11, RGS11 $\mathrm{D}$, and RGS11*(PW274AS), full-length RGS6, RGS6 $\Delta$ D, and RGS6*(D297A) constructs were tagged with an N-terminal hemagglutinin epitope and subcloned into the pcDNA3.1 vector as described (Snow et al., 1998, 1999). RGS2, RGS4, and untagged RGS11 constructs, cloned into the mammalian expression vector pcDNA3.1, were gifts from Drs. A. Gilman and A. Krumins (University of Texas Southwestern Medical Center).

Cell culture and transient transfection. The C2D7 cell line, derived from HEK293 cells stably expressing the $\mathrm{N}$-type $\mathrm{Ca}$ channel $\alpha_{1 \mathrm{~B}}, \alpha_{2} \delta$, and $\beta_{1-3}$ subunits (Simen and Miller, 1998, 2000), was kindly provided by SIBIA Neurosciences and kept in medium (11995DMEM, $1 \%$ penicillin/streptomycin, $5 \%$ bovine calf serum, $0.5 \mathrm{~g} / \mathrm{l}$ geneticin, and $70 \mu \mathrm{l} / 500 \mathrm{ml}$ hygromicin). The cells were transfected with $5 \mu \mathrm{g}$ of G-protein $\beta$ subunit, $5 \mu \mathrm{g}$ of G-protein $\gamma$ subunit, and $1 \mu \mathrm{g}$ of GFP DNA, using the polyethylenimine method as described by Boussif et al. (1995). In RGS cotransfection experiments, different amounts of $\mathrm{G} \beta, \mathrm{G} \gamma$, and RGS DNA were used as indicated in the text. Successfully transfected cells were identified by GFP fluorescence.

Electrophysiological recording. At $40-72 \mathrm{hr}$ after transfection, total $\mathrm{Ba}^{2+}$ currents were measured using the whole-cell patch-clamp technique. The coverslips were mounted in a perfusion chamber and constantly perfused by a gravity feed system with a modified HEPES-balanced external solution $(151 \mathrm{~mm}$ tetraethylammonium chloride, $10 \mathrm{~mm}$ HEPES, $5 \mathrm{~mm} \mathrm{BaCl}$, $1 \mathrm{mM} \mathrm{MgCl}_{2}$, and $10 \mathrm{~mm}$ glucose, $\mathrm{pH}$ adjusted to 7.4 and osmolarity to 310 mOsm) to isolate the $I_{\mathrm{Ba}}$. Pipettes of 3-5 $\mathrm{M} \Omega$ were pulled from microhematocrit capillary tubes (VWR Scientific, West Chester, PA) with a Flaming-Brown P-97 micropipette puller (Sutter Instrument Co., Novato, CA). The pipette solution contained $100 \mathrm{~mm} \mathrm{CsCl}, 1 \mathrm{~mm} \mathrm{MgCl}{ }_{2}, 10 \mathrm{~mm}$ HEPES, $10 \mathrm{~mm}$ BAPTA, $3.6 \mathrm{~mm}$ MgATP, $14 \mathrm{~mm}$ phosphocreatine (CrP), $0.1 \mathrm{~mm}$ LiGTP, and $50 \mathrm{U} / \mathrm{ml}$ creatine phosphokinase $(\mathrm{CrPK}) ; \mathrm{pH}$ was adjusted to 7.2 with $\mathrm{Cs}(\mathrm{OH})$, and osmolarity was near $290 \mathrm{mOsm}$. The tip solution was similar to the pipette solution without MgATP, CrP, LiGTP or CrPK.

$I_{\mathrm{Ba}}$ was measured and recorded with an Axopatch 200B (Axon Instruments, Foster City, CA) using the Clampex program (pClamp 6 software suite; Axon Instruments). Data were digitized at $10 \mathrm{kHz}$ and filtered at 5 $\mathrm{kHz}$. Series resistance was compensated to $70 \%$, and currents were leakcorrected on-line using a P4 protocol. Prepulse experiments were performed using a prepulse protocol consisting of a $50 \mathrm{msec}+10 \mathrm{mV}$ depolarization test pulse from $-80 \mathrm{mV}$ holding potential with (test pulse 2) or without (test pulses 1) a $50 \mathrm{msec}+80 \mathrm{mV}$ prepulse (Fig. $1 \mathrm{~A}$ ). There was a $5 \mathrm{msec}-80 \mathrm{mV}$ interval between the prepulse and test pulse. Currents were analyzed off-line using the Clampfit program. Facilitation was indicated by calculating the "facilitation ratio" (P2/P1), which we defined as the peak current of test pulse 2 divided by the current of test pulse 1 at the same time point (See Simen and Miller, 1998). This time point was normally between 6 and $15 \mathrm{msec}$ after the start of the depolarizing test pulse. All experiments and solutions were used at room temperature.

Statistical analysis for multiple comparisons was performed using oneway ANOVA followed by a nonparametric Kolmogorov-Smirnov test. The unpaired $t$ test was used for two-group comparison. $p<0.01$ was considered statistically significant.

Northern blots. Total RNA was isolated from transfected (48 hr) C2D7 cells using the guanidine thiocyanate-phenol method (Trizol reagent; Life Technologies). Total RNA from untransfected cells was used as a control. Twenty micrograms of RNA for each sample were separated on formaldehyde-agarose gels and transferred to Hybond- $\mathrm{N}^{+}$nylon membranes (Amersham Pharmacia Biotech). Each $\beta$ subunit was probed with a subunit-specific oligonucleotide $(\beta 1$, TTCCCACTGGGTCGATGTTGTTTGTG; $\beta 2$, GGAGCAGATGTTGTCCAACC; $\beta 3$, AATGAAGAGATTGAAGTCAGGAGACAC; $\beta 4$, TCCCGAACTTGTAATGATTT GTCCA; 35: CGTGCAGGGCATGGTGACCGCGTGCT). The probe was labeled with T4 polynucleotide kinase (New England Biolabs, Beverly, MA) and $\left[\gamma^{32} \mathrm{P}\right]$ ATP $(6000 \mathrm{Ci} / \mathrm{mmol}$; Amersham Pharmacia Biotech). Membranes were prehybridized for $2 \mathrm{hr}$ at $42^{\circ} \mathrm{C}(6 \times$ SSPE, $5 \times$ Denhardt's solution, $0.1 \%$ SDS, and $100 \mu \mathrm{g} / \mathrm{ml}$ boiled salmon sperm DNA) and hybridized at $42^{\circ} \mathrm{C}$ overnight (prehybridization solution plus labeled probes). The blots were washed in $5 \times$ SSC and $0.5 \%$ SDS at room temperature for $10 \mathrm{~min}$ and in $0.5 \times \mathrm{SSC}$ and $0.1 \%$ SDS at $42^{\circ} \mathrm{C}$ for $10-60 \mathrm{~min}$.

\section{RESULTS}

We subcloned human G-protein $\beta 1, \beta 2, \beta 3$, and $\beta 5$ and mouse (m) $\beta 4$ into CMV vectors. All $\beta$ subunits were sequenced and matched sequences formerly reported, with the exception that the $\mathrm{m} \beta 4$ sequence showed four differences from that reported in the database (M87286). As previously observed (Snow et al., 1999), there were two silent mutations at positions $433(\mathrm{~A} \rightarrow \mathrm{G})$ and 634 $(\mathrm{G} \rightarrow \mathrm{C})$, and differences at positions $434(\mathrm{G} \rightarrow \mathrm{A})$ and $458(\mathrm{G} \rightarrow \mathrm{C})$ corresponded to Asp $\rightarrow$ Asn and Ala $\rightarrow$ Pro substitutions. Three independent clones were sequenced, and all showed the same changes.

We examined the effects of overexpressing different G-protein $\beta$ subunits on cloned human $\alpha_{1 \mathrm{~B}}$ (N-type) Ca channels $\left(\alpha_{1 \mathrm{~B}-1}, \alpha_{2} \delta\right.$, and $\beta_{1-3}$ ) stably expressed in HEK293 cells (C2D7 cells). In control cells, a $50 \mathrm{msec}$ depolarizing test pulse to $+10 \mathrm{mV}$ elicited a rapidly activating and slowly inactivating $I_{\mathrm{Ba}}$, which was not significantly altered by a $50 \mathrm{msec}$ prepulse to $+80 \mathrm{mV}$ (Fig. $1 A$ ). To study the ability of different $\mathrm{G}$ protein $\beta / \gamma$ dimers to inhibit the $I_{\mathrm{Ba}}$, we transiently transfected C2D7 cells with different G-protein $\beta$ subunits, together with $\gamma 3$ subunits and GFP DNA. Ba currents were only recorded from GFP fluorescent cells. Expression of $\beta 1 \gamma 3$ subunits in C2D7 cells reduced the $I_{\mathrm{Ba}}$ amplitude and slowed its activation rate (Fig. $1 B$, trace 1 ). The inhibition was "relieved" by a depolarizing prepulse (Fig. $1 B$, trace 2). The resulting "facilitation ratio" (see Materials and Methods) has frequently been used as an index of voltage-dependent, membrane-delimited inhibition of $\mathrm{Ca}$ channels by $\mathrm{G}$ protein $\beta / \gamma$ subunits (Simen and Miller, 1998, $2000)$. In addition, the $I-V$ curve for the $I_{\mathrm{Ba}}$ was shifted to the left by $\sim 10-15 \mathrm{mV}$ after the prepulse (Fig. $1 B$, bottom traces). As did Garcia et al. (1998), we observed that both $\beta 1 \gamma 3$ and $\beta 2 \gamma 3$ inhibited $\mathrm{N}$-type currents in a voltage dependent manner, with facilitation ratios of $1.76 \pm 0.16$ and $1.87 \pm 0.21$, respectively (Fig. $1 B, C$ ). In contrast to Garcia et al. (1998), we found that $\beta 4 \gamma 3$ and $\beta 3 \gamma 3$ also significantly inhibited the $I_{\mathrm{Ba}}$ (Fig. $1 D, E$ ). $\beta 4 \gamma 3$ and $\beta 3 \gamma 3$ produced facilitation ratios of $2.01 \pm 0.18$ and $1.50 \pm 0.12$, respectively. However, no effects were observed in cells transfected with $G \beta 5 \gamma 3$ DNA (Fig. $1 F$ ). Moreover, overexpression of any $\beta$ subunits alone failed to produce inhibition of the $I_{\mathrm{Ba}}$ (data not shown). To exclude the possibility that the inability of $\beta 5 \gamma 3$ to inhibit the $I_{\mathrm{Ba}}$ was attributable to a failure to express the $\beta 5$ subunit, total RNA was isolated from transfected cells and probed with $\beta$ subunit-specific oligonucleotides. Each $\beta$ subunit was expressed as a transcript of $\sim 1.2 \mathrm{~kb}$ (Fig. 2).

To further assess the potential role of G-protein $\gamma$ subunits, we investigated the ability of other combinations between $\beta 1-\beta 4$ and $\gamma 1-\gamma 3$ to inhibit the $I_{\mathrm{Ba}}$. These results are summarized in Figure 3 . For $\beta \gamma 1$ combinations, $\beta 1 \gamma 1$ exhibited the largest facilitation ratio (1.72 \pm 0.14$) . \beta 2 \gamma 1, \beta 3 \gamma 1$, and $\beta 4 \gamma 1$ exhibited smaller effects, although they were still significantly different from control (one-way ANOVA, $p<0.01)$. As with $\beta 5 \gamma 3, \beta 5 \gamma 1$ failed to inhibit the $I_{\mathrm{Ba}}$. $\beta \gamma 2$ combinations showed similar facilitation ratios for $\beta 1-\beta 4$ as did $\beta \gamma 3$ and $\beta \gamma 1$ combinations. A striking difference, however, was that $\beta 5 \gamma 2$ strongly inhibited the $I_{\mathrm{Ba}}$, exhibiting a facilitation ratio of $1.76 \pm 0.07$.

It is interesting to note that $\mathrm{G}$ protein $\gamma$ subunits are not the only proteins that can potentially form heterodimers with $\beta$-subunits. RGS6, 7, 9, and 11 belong to a subfamily of G protein $\alpha$-subunit GTPase-activating proteins (GAPs) that contain a $\gamma$-subunit-like (GGL) domain (Hepler, 1999; Siderovski et al., 1999). It has been shown that GGL domain-containing RGS proteins form heterodimers with G $\beta 5$ (Snow et al., 1998, 1999; Posner et al., 1999), raising the possibility that $\beta 5 / \mathrm{RGS}$ heterodimers could effectively inhibit Ca channels or that RGS proteins could act as "antagonists" by inhibiting the interaction between $\gamma 2$ and $\beta 5$. The next series of experiments were designed to investigate these possibilities. Coexpression of the GGL domain containing RGS11 with G $\beta 5$ did not result in $\mathrm{Ca}$ channel inhibition (data not shown). Furthermore, neither RGS11 nor G $\beta 5$ expressed alone produced any effect on the $I_{\mathrm{Ba}}$ (Fig. $4 A$; data not shown for $\mathrm{G} \beta 5$ alone). Interestingly, however, we observed that coexpression of RGS6 or RGS11 with $\beta 5 \gamma 2$ was able to antagonize the effects of the $\beta / \gamma$ heterodimers (Fig. 5). Thus, increasing the ratio of RGS11 to $\gamma 2$ in the transfection produced a dose-dependent reduction in the facilitation ratio 

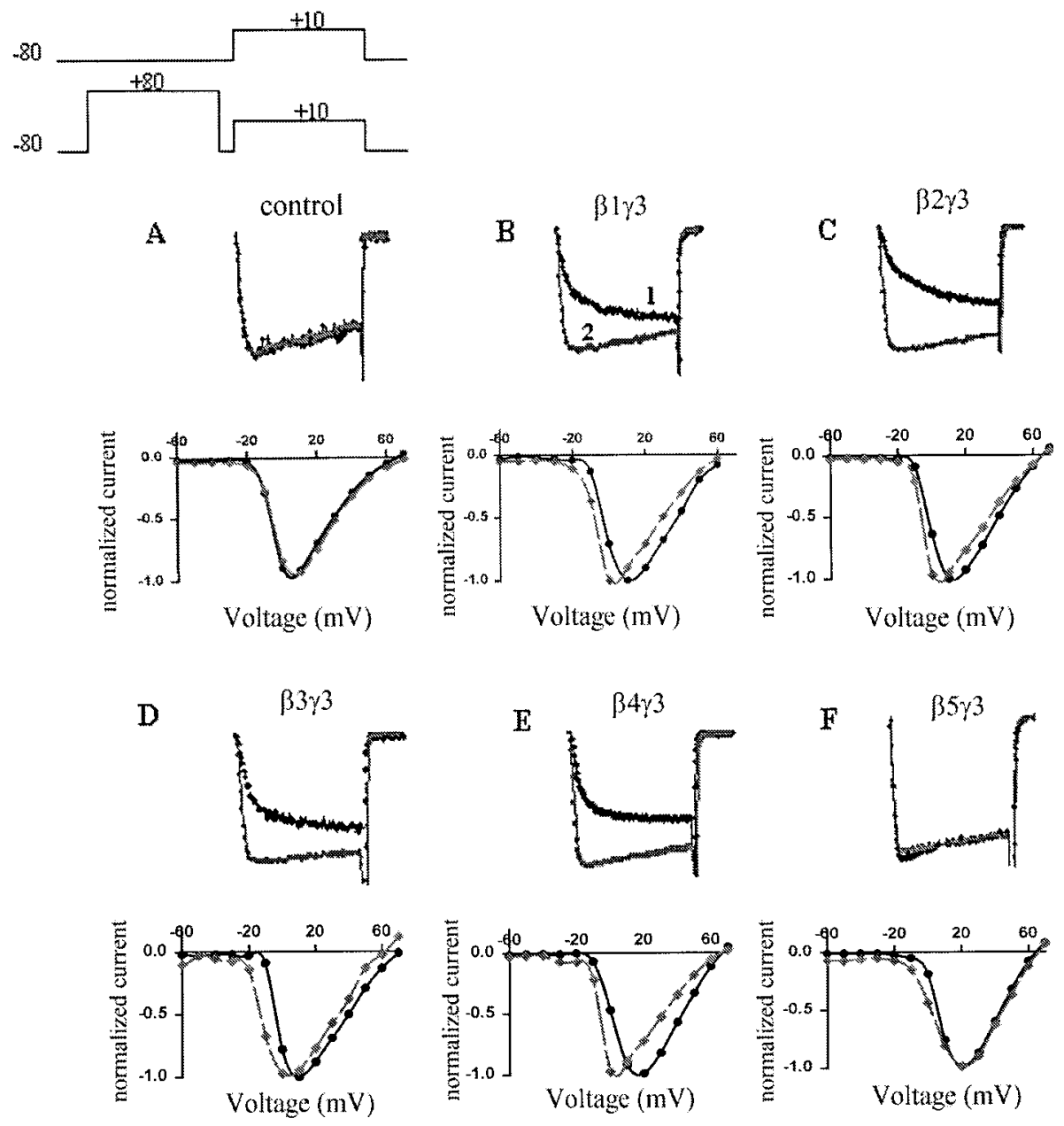

Figure 1. Effects of different $\mathrm{G} \beta$ subunits on barium current facilitation. Top panel, Superimposed $I_{\mathrm{Ba}}$ during a $50 \mathrm{msec}$ depolarization to $+10 \mathrm{mV}$ from $-80 \mathrm{mV}$ holding potential, without (trace 1) and with (trace 2) a $50 \mathrm{msec}+80 \mathrm{mV}$ prepulse. Bottom panels, Leftward shift of the $I-V$ curve after the prepulse (dashed gray line). Currents were recorded 40-72 hr after transfection of C2D7 cells with GFP alone $(A)$ or with G-protein $\beta 1(B), \beta 2(C), \beta 3(D)$, $\beta 4(E)$, or $\beta 5(F)$, expressed together with $\mathrm{G} \gamma 3$.

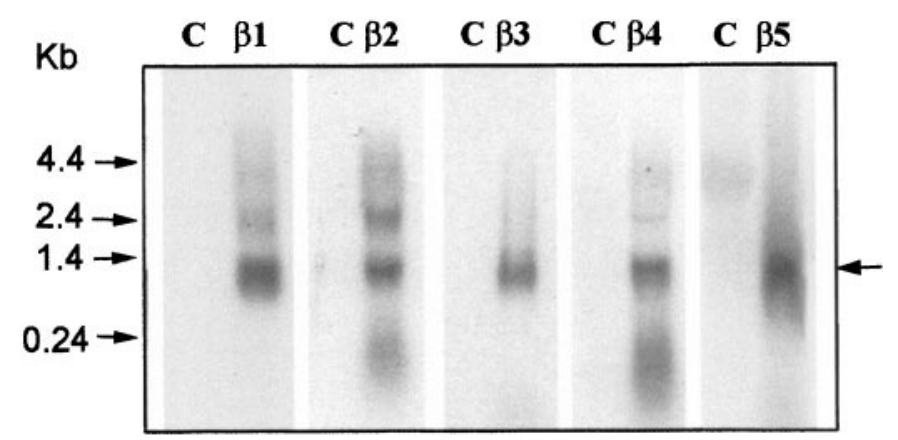

Figure 2. Northern blot of $\mathrm{G}$ protein $\beta$ subunit expression. Total mRNA $(20 \mu \mathrm{g})$ isolated from untransfected $\mathrm{C}_{2} \mathrm{D}_{7}$ cells (as control, $C$ ) and cells transfected with different $G$ protein $\beta$ subunits (as marked) were hybridized with subunit-specific oligonucleotide probes (see Materials and Methods). Positions of the RNA size standards (in kilobases) are shown on the left. Heterologously expressed $\mathrm{G} \beta$ subunits are marked with an arrow on the right. Endogenous $\mathrm{G} \beta$ subunits were expected to have similar sizes. However, because they were expressed in much lower amounts, they would not be detected under these experimental conditions.

observed (Fig. 4A). This inhibition was selective for the $\beta 5 \gamma 2$ combination; when RGS11 was coexpressed at an 8:1 ratio to $\gamma 2$, together with $\beta 2$, no reduction in the effects of the $\beta 2 \gamma 2$ subunits was observed (Fig. 4B). It has been shown that point mutations in the GGL domain (D297A in RGS6 and PW274AS in RGS11) abolish the interaction between GGL-containing RGS proteins and G $\beta 5$ (Snow et al., 1999). Expression of full-length RGS6/11 cDNA constructs with these mutations failed to block the effects of $\mathrm{G} \beta 5 \gamma 2$ (Fig. 5), thus supporting the role of the GGL domain in the interaction between RGS11 and $\beta 5 \gamma 2$.
All four of the GGL-containing RGS proteins, RGS6, 7, 9, and 11, contain a DEP (dishevelled/Egl-10/pleckstrin) domain as well as GGL and RGS domains. To further answer the question of which domain(s) is involved in the interaction with $\mathrm{G} \beta 5 \gamma 2$, we made two constructs consisting of the N-terminal (RGS11n) and C-terminal (RGS11c) halves of the RGS11 protein, with RGS11n containing the DEP and GGL domains and RGS11c containing the RGS domain and a C-terminal tail (Fig. 6B). At an 8:1 ratio, cotransfection of the RGS11n construct reduced the facilitation ratio produced by $\mathrm{G} \beta 5 \gamma 2$ to a degree similar to that observed with the full-length RGS11. However, cotransfection of RGS11c did not reduce the facilitation ratio significantly (Fig. $6 \mathrm{C}$ ). In accordance with this result, RGS2 and RGS4 proteins, which contain only an RGS domain, failed to reduce the facilitation ratio when coexpressed with G $\beta 5 \gamma 2$ (Fig. $6 C$ ). To further address the question of whether the DEP domain is a requirement for interaction with G $\beta 5$, the DEP domains of RGS6 and RGS11 were deleted. Both constructs blocked the facilitation by $\mathrm{G} \beta 5 \gamma 2$ to an extent similar to that of full-length RGS6 and RGS11 (Fig. 6C).

\section{DISCUSSION}

Voltage-dependent inhibition of $\mathrm{Ca}$ channels is thought to be mediated by direct binding of $\mathrm{G}$ protein $\beta / \gamma$ subunits to one or more sites on the $\alpha_{1}$ subunit of the $\mathrm{Ca}$ channel (Herlitze et al., 1996; Ikeda 1996; Simen and Miller, 1998, 2000). An important question is how selectivity can be imparted to this process. That this is indeed important is indicated by studies showing that the productive activation of some GPCRs, particularly those linked to the $\alpha_{\mathrm{q}}$ family of heterotrimeric $\mathrm{G}$ proteins, does not produce voltage dependent inhibition of $\mathrm{Ca}$ channels, or at least rather little in comparison with other receptors (see introductory remarks). Because the activation of all GPCRs presumably results in the 

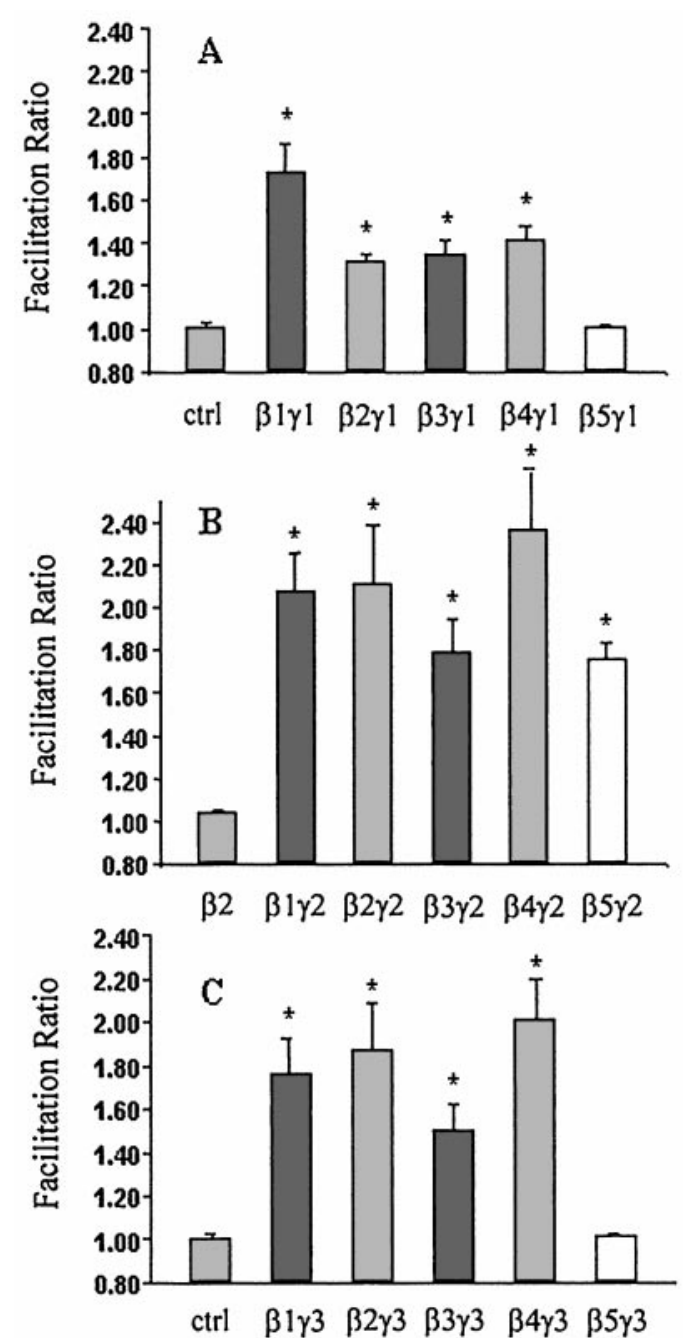

Figure 3. Summary of facilitation ratios for barium current inhibition after transfection of different $\mathrm{G} \beta \gamma$ combinations. G-protein $\beta$ subunits were coexpressed with $\mathrm{G} \gamma 1(A), \mathrm{G} \gamma 2(B)$, and $\mathrm{G} \gamma 3$ (C). $\mathrm{G} \beta$ expressed alone did not produce facilitation of $I_{\mathrm{Ba}}$, as represented by $\mathrm{G} \beta 2$ in $B$. Data are plotted as mean $\pm \mathrm{SEM}$; ${ }^{*} p<0.01$, one-way ANOVA analysis followed by nonparametric Kolmogorov-Smirnov test $(n=7 \sim 15)$.

release of $\beta / \gamma$ subunits, it is unclear what factors underlie specificity. However, because the precise composition of the heterotrimeric $G$ proteins that interact with each receptor presumably differs, this may dictate specificity in some manner that is not currently understood. One important possibility is that not all combinations of $\beta / \gamma$ heterodimers are able to inhibit $\mathrm{Ca}$ channels. Considering that there are at least 5 different $\beta$ subunits and at least 11 types of $\gamma$ subunits, the number of possible combinations is very large (Morris and Malbon, 1999). Garcia et al. (1998), examined the ability of all of the known $\beta$ subunits to produce Ca channel inhibition when they overexpressed them in rat SCG neurons. They observed that only $\beta 1$ and $\beta 2$ produced strong $\mathrm{Ca}$ channel inhibition. Our results complement those of Garcia et al. (1998) in certain important respects. We have shown that all of the $\beta$ subunits can in fact produce strong $\mathrm{Ca}$ channel inhibition, but that this may depend critically on the nature of the $\gamma$-subunit involved. For example, although $\beta 1-\beta 4$ are effective when combined with $\gamma 1,2$, or $3, \beta 5$ is only effective when expressed with $\gamma 2$. Similar conclusions can be drawn from the recent work of Ruiz-Velasco and Ikeda (2000). These results indicate that it is possible that in the SCG neurons used by Garcia et al. (1998), $\gamma 2$ was not highly expressed, or that any other $\gamma$ subunits that form heterodimers with $\beta 5$ are also probably ineffective (Watson et al., 1994, 1996). Other explanations are also possible (see below).
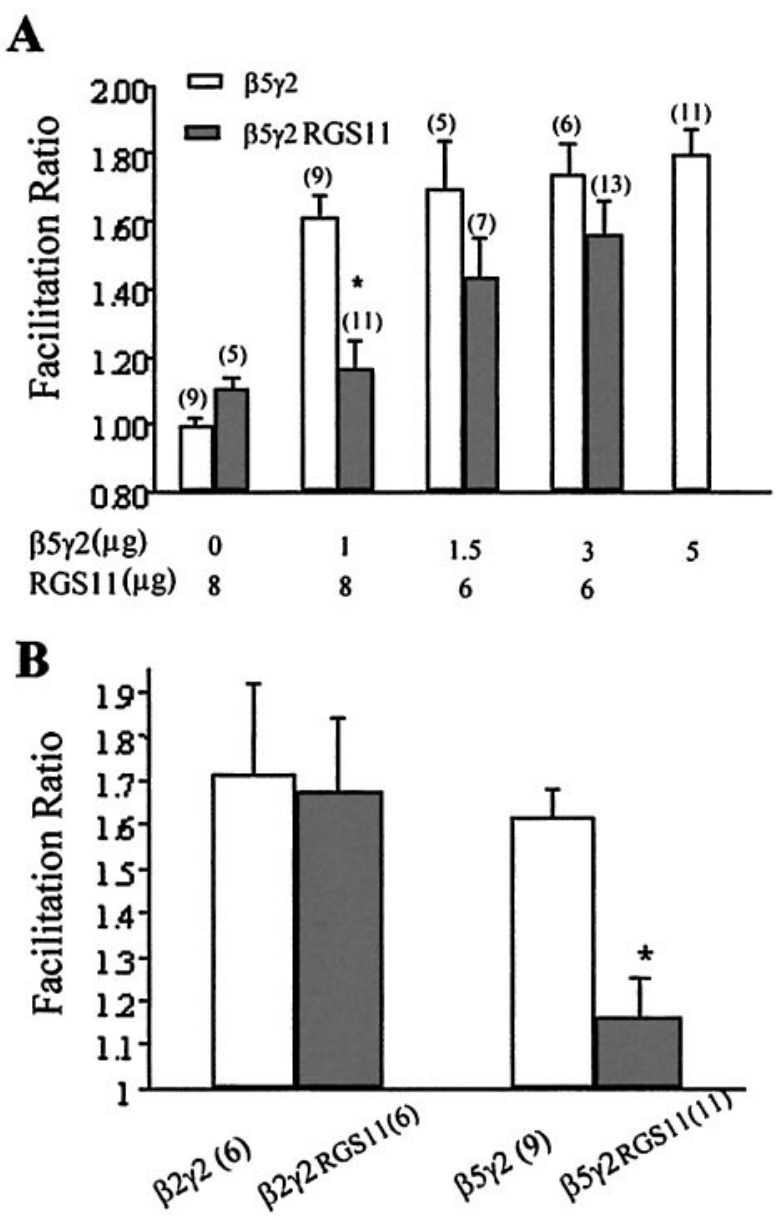

Figure 4. RGS11 antagonized the effects of $\beta 5 \gamma 2$. Increasing the ratio of RGS11 to $\gamma 2$ reduced the $I_{\mathrm{Ba}}$ facilitation ratio produced by $\beta 5 \gamma 2(A)$. However, RGS11 did not antagonize the effects of $\beta 2 \gamma 2(B)$. In the second set of experiments $(B), 8 \mu \mathrm{g}$ of RGS11 was cotransfected with $1 \mu \mathrm{g}$ of $\beta 2 \gamma 2$ or $\beta 5 \gamma 2$. Numbers of experiments are in parentheses. Data are plotted as mean \pm SEM; ${ }^{*} p<0.01$, unpaired $t$ test between $\beta 5 \gamma 2$ and $\beta 5 \gamma 2 \mathrm{RGS} 11$.

The observation that only $\gamma 2$ was effective in combination with $\beta 5$ is consistent with several other observations in the literature. It has been shown that $\beta 5$ will associate with several different $\gamma$ subunits, including $\gamma 2,4,5$, and 7 (Watson et al., 1994, 1996). Comparison of the functional effects of these heterodimers is limited. However, $\beta 5 \gamma 2$ was shown to be a far more effective activator of phospholipase C (PLC)- $\beta 2$ than either $\beta 5 \gamma 4$ or $\beta 5 \gamma 7$ (S. Zhang et al., 1996). On the other hand, none of these combinations proved to be effective activators of the MAPK and JNK pathways, although they were all effective in combination with $\beta 1$ (S. Zhang et al., 1996). Thus, $\beta 5$-containing heterodimers are not effective in all signaling pathways. Clearly, in the case of $\mathrm{N}$-type $\mathrm{Ca}$ channels, the $\beta 5 / \gamma 2$ combination is effective, but $\beta 5 \gamma 1$ and $\beta 5 \gamma 3$ are not. Of particular interest in this regard are observations that $\beta 5 \gamma 2$ heterodimers are selectively found in association with $\alpha_{\mathrm{q}}$ or other members of this family of heterotrimeric $\mathrm{G}$ proteins (Fletcher et al., 1998). Thus, activation of receptors such as the M1 muscarinic receptor, the ET1 endothelin receptor, or other $\alpha_{\mathrm{q}}$ linked receptors can be expected to release $\beta 5 \gamma 2$ subunits (Lindorfer et al., 1998). Because we have now shown that these heterodimers are effective inhibitors of $\alpha_{1 \mathrm{~B}} \mathrm{Ca}$ channels, it is unlikely that this explains the ineffectiveness of $\alpha_{\mathrm{q}}$-linked GPCRs in inhibiting Ca channels.

The structure of the $\beta 5$ subunit is the most unusual of all of the $\beta$ subunits, being only $\sim 50 \%$ identical to $\beta 1-\beta 4$, all of which are very similar to one another (Morris and Malbon, 1999). It has recently been shown that the $\beta 5$ subunit can associate not only with $\gamma$ subunits but also with proteins of the RGS family that possess $\gamma$ subunit-like GGL domains (Hepler, 1999; Siderovski et al., 1999). 
A
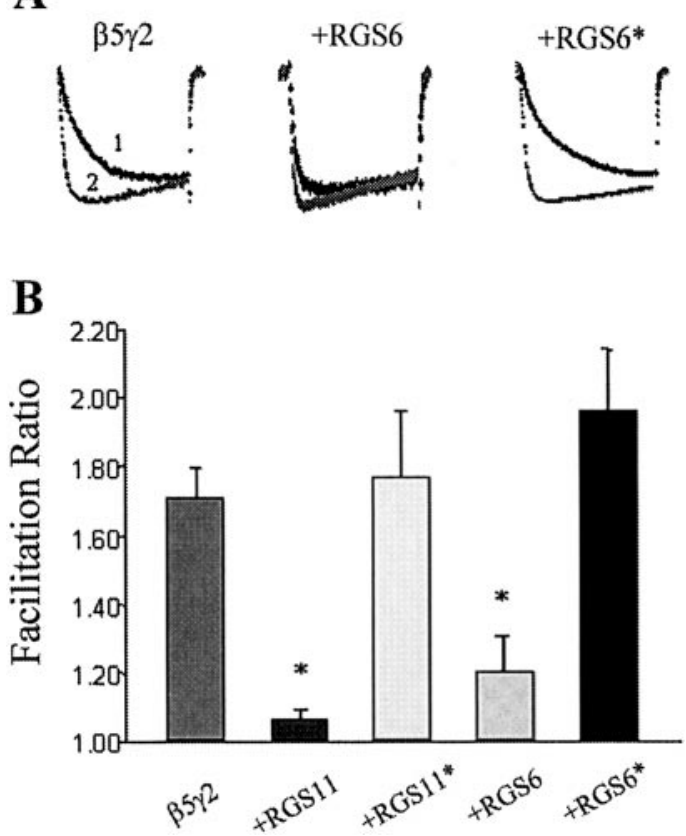

Figure 5. RGS6 and RGS11 antagonism of G $\beta 5 \gamma 2$ facilitation of Ca currents depends on their GGL domains. RGS6 and RGS11 constructs were cotransfected with $\mathrm{G} \beta 5 \gamma 2$ at an 8:1 ratio. (RGS6* and $R G S 11^{*}$ represent full-length cDNA constructs with mutations in the GGL domain that inhibit binding to $\beta 5$; see Results and Snow et al., 1999). A, Typical current traces with (trace 2) or without (trace 1) prepulse. B, Summary of facilitation ratios for $I_{\mathrm{Ba}}$ inhibition after cotransfection with $\beta 5 \gamma 2$ and different RGS constructs. Data are plotted as mean $\pm \mathrm{SEM} ;{ }^{*} p<0.01$, one-way ANOVA analysis followed by nonparametric Kolmogorov-Smirnov test $(n=6 \sim 15)$.

The question arises of the biological significance of these $\beta 5 / \mathrm{RGS}$ heterodimers. One possibility is that they might support the same effector signaling events as $\beta 5 / \gamma 2$ heterodimers. However, as we demonstrate here, this does not necessarily appear to be the case. Coexpression of $\beta 5$ with RGS11 did not produce $\mathrm{Ca}$ channel inhibition. It has been shown biochemically that overexpression of $\beta 5$ (but not $\beta 1-\beta 4$ ) with GGL-containing RGS proteins does actually lead to the formation of tight complexes in the cytosol of cells (Snow et al., 1998, 1999; Posner et al., 1999; Liang et al., 2000). Thus, it is unlikely that the lack of effect of the RGS11 seen in our experiments is attributable to the lack of formation of heterodimers. Recently, Posner et al. (1999) and Snow et al. (1998) demonstrated that although heterodimers formed between RGS6, 7 , or 11 and $\beta 5$ possessed appreciable GAP activity, they were ineffective in activating or inhibiting adenylate cyclases I and II and were also unable to antagonize the ability of $\beta 1 \gamma 2$ to activate cyclase. In addition, neither $\beta 5 /$ RGS complex was able to activate PLC- $\beta 2$, although high concentrations of the heterodimer had a small inhibitory effect on the enzyme activated by $\beta 1 \gamma 2$ (Posner et al., 1999). Thus, the lack of effect of $\beta 5 / \mathrm{RGS} 11$ complexes on $\mathrm{Ca}$ channels mirrors other data indicating that these complexes are generally inactive in traditional assays of $\beta / \gamma$-mediated signal transduction.

On the other hand, it is also possible that GGL-containing RGS proteins might compete with $\gamma 2$ for $\beta 5$ subunits and therefore antagonize the effects of the $\beta 5 \gamma 2$ heterodimer. Indeed, it has been proposed that GGL-containing RGS proteins have a higher affinity for $G \beta 5$ than $G \gamma 2$ does, because conversion from phenylalanine (Phe-61) within G $\gamma 2$ to tryptophan (Trp-274) at the analogous position found within GGL domains of RGS proteins increases $\mathrm{G} \beta 5 / \gamma 2$ binding under low-detergent conditions (Snow et al., 1999). We have now obtained evidence for this competing interaction, although the relative affinities of the binding partners cannot be accurately assessed from our experiments. Thus, coexpression of both RGS6 and RGS11 blocked the inhibitory effects of $\beta 5 \gamma 2$ on
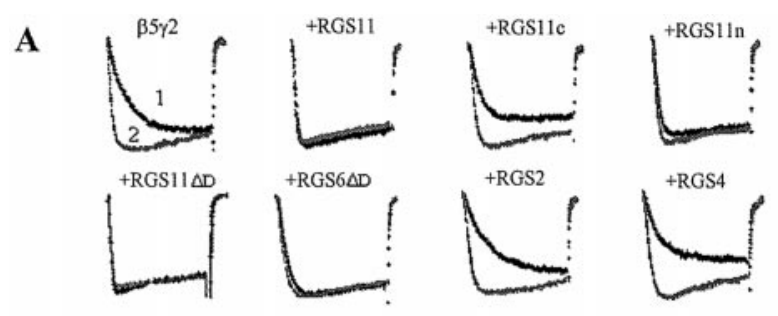

B

C

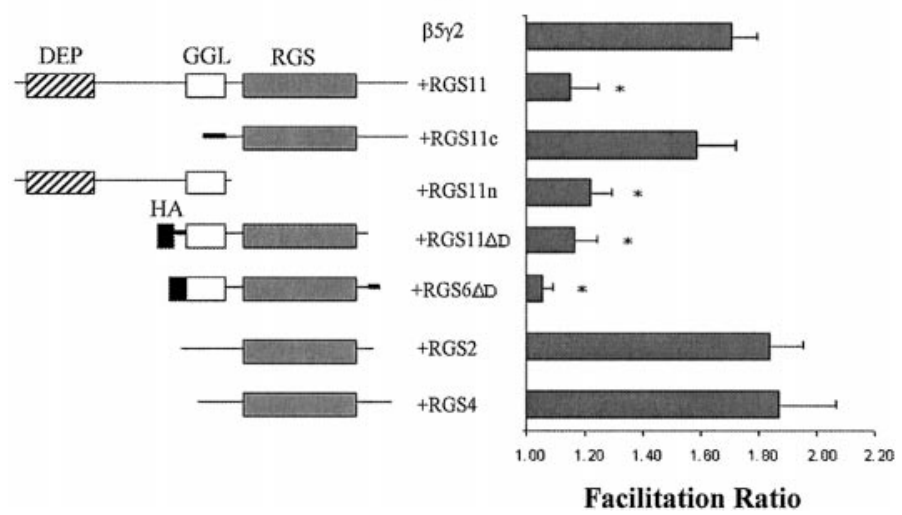

Figure 6. RGS protein constructs have different abilities to antagonize $I_{\mathrm{Ba}}$ inhibition by $\beta 5 \gamma 2$. Various RGS constructs were cotransfected with $G \beta 5 \gamma 2$ at an 8:1 ratio. $A$, Typical current traces with (trace 2) or without (trace 1 ) prepulse. $B$, Schematic structures of different RGS protein constructs. Artificial linkers or termini are drawn in thick lines. Hatched boxes, DEP domain; open boxes, GGL domain; filled boxes, hemagglutinin $(H A)$ epitope; gray boxes, RGS domain. $C$, Summary of facilitation ratios for $I_{\mathrm{Ba}}$ inhibition after cotransfection with $\beta 5 \gamma 2$ and different RGS protein constructs. Data are plotted as mean $\pm \mathrm{SEM} ;{ }^{*} p<0.01$, one-way ANOVA analysis followed by nonparametric Kolmogorov-Smirnov test $(n=8 \sim 15)$.

Ca channels, although they were unable to block the effects of $\beta 2 \gamma 2$. The role of the GGL domains in these effects is clear from the fact that mutations that prevent binding of the GGL domain to $\beta 5$ also prevented the effect of RGS6 and 11. Furthermore, when we cut the RGS11 proteins into two sections, the portion containing the GGL and DEP domains inhibited the effect of $\beta 5 \gamma 2$, whereas the portion containing the RGS domain did not. The function of the DEP domain is unclear. It has been suggested that DEP domains may play a role in membrane targeting of proteins (Axelrod et al., 1998). However, in the present case, deletion of the DEP domains from RGS6 or 11 did not abolish their effects on $\beta 5 \gamma 2$. Thus, our data are consistent with the possibility that GGLcontaining RGS proteins may regulate $\beta 5 \gamma 2$-dependent inhibition of $\mathrm{Ca}$ channels through interaction of their GGL domains with $\beta 5$. In support of this possibility, $\beta 5 /$ RGS6 and $\beta 5 /$ RGS7 complexes have been isolated from the brain (Liang et al. 2000, Zhang and Simonds, 2000). It is also possible that the decreased effectiveness observed by Garcia et al. (1998) and Ruiz-Velasco and Ikeda (2000) when $\beta 5$ was expressed in SCG neurons reflects the expression of GGL-containing RGS proteins in these neurons.

In summary, our results indicate that all of the known G-protein $\beta$ subunits are capable of producing rapid, voltage-dependent inhibition of $\mathrm{Ca}$ channels, although this ability may depend on the type of $\gamma$-subunit found in the heterodimer. Because all of the $\beta$ subunits are highly expressed in the nervous system (Betty et al., 1998), it is likely that they may all participate in the receptormediated regulation of $\mathrm{Ca}$ channels. Thus, the reasons why activation of some GPCRs does not produce strong $\mathrm{Ca}$ channel inhibition may not simply depend on the selectivity of $\beta / \gamma$ heterodimers for Ca channel inhibition (Garcia et al., 1998). Our data also suggest that GGL-containing RGS proteins may act as antagonists of heterotrimeric $G$ proteins in two ways. First, they can act as GAP proteins for G-protein $\alpha$ subunits, and second, as we show here, they may act as antagonists of $\beta 5 \gamma 2$ heterodimers through their interactions with $\beta 5$ subunits. 


\section{REFERENCES}

Axelrod JD, Miller JR, Shulman JM, Moon RT, Perrimon N (1998) Differential recruitment of Dishevelled provides signaling specificity in the planar cell polarity and Wingless signaling pathways. Genes Dev 12:2610-2622.

Bernheim L, Beech DJ, Hille B (1991) A diffusible second messenger mediates one of the pathways coupling receptors to calcium channels in rat sympathetic neurons. Neuron 6:859-867.

Betty M, Harnish SW, Rhodes KJ, Cockett MI (1998) Distribution of heterotrimeric G-protein $\beta$ and $\gamma$ subunits in the rat brain. Neurosci 85:475-486.

Boussif O, Lezoualch F, Zania MA, Mergny MD, Scherman D, Demeneix B, Behr JP (1995) A versatile vector for gene and oligonucleotide transfer into cells in culture and in vivo: polyethylenimine. Proc Natl Acad Sci USA 92:7297-7301.

Canti C, Page KM, Stephens GJ, Dolphin AC (1999) Identification of residues in the $\mathrm{N}$ terminus of $\alpha 1 \mathrm{~B}$ critical for inhibition of the voltagedependent calcium channel by $G \beta \gamma$. J Neurosci 19:6855-6864.

Fletcher JE, Lindorfer MA, De Filippo JM, Yasuda H, Guilmard M, Garrison JC (1998) The G-protein $\beta 5$ subunit interacts selectively with the $\mathrm{Gq} \alpha$ subunit. J Biol Chem 273:636-644.

Garcia DE, Li B, Garcia-Ferreiro RE, Hernandez-Ochoa EO, Yan K, Gautam N, Catterall WA, Mackie K, Hille B (1998) G-protein $\beta$-subunit specificity in the fast membrane delimited inhibition of $\mathrm{Ca}$ channels. J Neurosci 18:9163-9170.

Hepler JR (1999) Emerging roles for RGS proteins in cell signaling. Trends Pharmacol Sci 20:376-382.

Herlitze S, Garcia DE, Mackie K Hille B, Scheuer T, Catterall WA (1996) Modulation of $\mathrm{Ca}$ channels by G-protein $\beta / \gamma$ subunits. Nature 380:258-262.

Hille B (1994) Modulation of ion channel function by G-protein coupled receptors. Trends Neurosci 17:531-536.

Ikeda SR (1996) Voltage dependent modulation of N-type calcium channels by G-protein $\beta / \gamma$ subunits. Nature 380:255-258.

Liang JJ, Chen HH, Jones PG, Khawaja XZ (2000) RGS7 complex formation and colocalization with the $\mathrm{G} \beta 5$ subunit in the adult rat brain and influence on G $\beta 5 \gamma 2$-mediated PLC $\beta$ signaling. J Neurosci Res 60:58-64.

Lindorfer MA, Myung CS, Savino Y, Yasuda H, Khazan R, Garrison JC (1998) Differential activity of the G-protein $\beta 5 \gamma 2$ subunit at receptors and effectors. J Biol Chem 273:34429-34436.

Liu NJ, Xu T, Xu C, Li CQ, Yu YX, Kang HG, Han JS (1995) Cholecystokinin octapeptide reverses $\mu$-opioid receptor mediated inhibition of calcium current in rat dorsal root ganglion neurons. J Pharmacol Exp Ther 275:1293-1299.

Margeta-Mitrovic M, Grigg JJ, Koyano K, Nakajima Y, Nakajima S (1997) Neurotensin and substance $\mathrm{P}$ inhibit low and high voltage activated $\mathrm{Ca}$ channels in cultured newborn rat nucleus basalis neurons. J Neurophysiol 78:1341-1352.

Miller RJ (1998) Presynaptic receptors. Annu Rev Pharmacol Toxicol 38:201-227.
Morris AJ, Malbon CC (1999) Physiological regulation of G-protein linked signalling. Physiol Rev 79:1373-1430.

Posner BA, Gilman AG, Harris BA (1999) Regulators of G-protein signalling 6 and 7. J Biol Chem 274:31087-31093.

Qin N, Platano D, Olcese R, Stefani E, Birnbaumer L (1997) Direct interaction of $\mathrm{G} \beta \gamma$ with a $\mathrm{C}$-terminal $\mathrm{G} \beta \gamma$-binding domain of the $\mathrm{Ca}^{2+}$ channel $\alpha 1$ subunit is responsible for channel inhibition by $\mathrm{G}$ proteincoupled receptors. Proc Natl Acad Sci USA 4:8866-8871.

Ruiz-Velasco V, Ikeda SR (2000) Multiple G-protein $\beta \gamma$ combinations produce voltage-dependent inhibition of $\mathrm{N}$-type calcium channels in rat superior cervical ganglion neurons. J Neurosci 20:2183-2191.

Shapiro MS, Hille B (1993) Substance P and somatostatin inhibit calcium channels in rat sympathetic neurons via different G-protein pathways. Neuron 10:11-20.

Shapiro MS, Wollmuth LP, Hille B (1994) Angiotensin 11 inhibits calcium and $M$ current channels in rat sympathetic neurons via G-proteins. Neuron 12:1319-1329.

Siderovski DP, Strockbine B, Behe CI (1999) Whither goest the RGS proteins? Crit Rev Biochem Mol Biol 34:215-251.

Simen AA, Miller RJ (1998) Structural features determining differential receptor regulation of neuronal Ca channels. J Neurosci 18:3689-3698.

Simen AA, Miller RJ (2000) Involvement of regions in domain I in the opioid receptor sensitivity of alpha1B Ca(2+) Channels. Mol Pharmacol 57:1064-1074.

Snow BE, Krumins AM, Brothers GM, Lee S, Wall MA, Chung S, Mangion J, Arya S, Gilman AG, Siderovske DP (1998) A G protein $\gamma$ subunit-like domain shared between RGS11 and other RGS proteins specifies binding to $G \beta 5$ subunits. Proc Natl Acad Sci USA 95:13307-13312.

Snow BE, Betts L, Mangion J, Sondek J, Siderovski DP (1999) Fidelity of $\mathrm{G}$ protein $\beta$-subunit association by the $\mathrm{G}$ protein $\gamma$-subunit-like domains of RGS6, RGS7, and RGS11. Proc Natl Acad Sci USA 96:6489-6494.

Taussig R, Sanchez R, Rifo M, Gilman AG, Belardetti F (1992) Inhibition of the $\omega$-conotoxin sensitive calcium current by distinct G-proteins. Neuron 8:799-809.

Watson AJ, Katz A, Simon MI (1994) A fifth member of the mammalian G-protein $\beta$-subunit family. J Biol Chem 269:22150-28160.

Watson AJ, Aragay AM, Slepak VZ, Simon MI (1996) A novel form of the G-protein $\beta$ subunit $G \beta 5$ is specifically expressed in the vertebrate retina J. Biol Chem 271:28154-28160.

Zhang JF, Ellinor PT, Aldrich RW, Tsien RW (1996) Multiple structural elements in voltage-dependent $\mathrm{Ca} 2+$ channels support their inhibition by G proteins. Neuron 17:991-1003.

Zhang JH, Simonds WF (2000) Copurification of brain G-protein beta5 with RGS6 and RGS7. J Neurosci 20(RC59):1-5.

Zhang S, Coso OA, Lee C, Gutkind JS, Simmonds WF (1996) Selective activation of effector pathways by brain specific Gprotein $\beta 5$. J Biol Chem 271:33575-33579. 